\title{
Saúde mental infantojuvenil e desastres: um panorama global de pesquisas e intervenções
}

\author{
Mental health in children and adolescents and disasters: a global \\ overview of research and interventions
}

\author{
Salud mental infantojuvenil y desastres: un panorama global de \\ investigaciones e intervenciones
}

\begin{abstract}
AN INTERNATIONAL PERSPECTIVE ON DISASTERS AND CHILDREN'S MENTAL HEALTH. Hoven CW, Amsel LV, Tyano S. Cham: Springer; 2019. 439 p. (Series: Integrating Psychiatry and Primary Care). ISBN 978-3-030-15872-9.
\end{abstract}

doi: 10.1590/0102-311X00064120

Saúde mental infantojuvenil e desastres são os conceitos basilares que norteiam o tom e o contexto de An International Perspective on Disasters and Children's Mental Health, livro sem tradução para o português. Partindo da abordagem de diferentes desastres globais por heterogêneos grupos de pesquisa e equipes de intervenção, é tecida uma perspectiva internacional sobre a relação entre eventos traumáticos em larga escala e saúde mental de crianças e adolescentes. A produção do livro é inspirada em pesquisas norte-americanas desenvolvidas após o atentado de 11 de setembro. O livro, contudo, permite democraticamente 1 que vozes do Norte e do Sul relatem múltiplas histórias e intervenções em saúde mental infantojuvenil após catástrofes mundiais vivenciadas nas últimas décadas.

Desastres são explicados como eventos traumáticos em larga escala, como catástrofes naturais, guerras e acidentes, capazes de afetar os sujeitos individual e coletivamente, ou seja, em suas histórias de vida e de maneira micro e macrossociais. Embora não seja possível predizer preci- samente tais eventos, mudanças ecológicas, desigualdades sociais e múltiplas violências são contextos que servem de alerta para sua ocorrência.

Partindo de uma perspectiva ecológica e desenvolvimental para abordar as questões de saúde debatidas no livro, os autores enfatizam aspectos biológicos, comportamentais e sociais 2 num continuum do curso de vida individual, em que fatores pré, peri, pós-natais e que seguem todo o ciclo de desenvolvimento, da infância à velhice, são compreendidos longitudinalmente. O enfoque na saúde mental se dá por sua grande carga de morbimortalidade no mundo, pela correlação comórbida entre as dimensões física e mental e por ser mais sensível às influências da (des)organização social.

A correlação entre os dois conceitos índices do livro segue esta premissa: desastres podem influenciar diretamente a saúde mental de um indivíduo, sendo também sua saúde mental, ao longo da vida, uma proxy da repercussão desses desastres em sua comunidade. Os autores discutem o grande impacto que os desastres representam para a saúde mental de crianças e adolescentes pela vulnerabilidade e dificuldade de compreensão que apresentam e pelas repercussões não apenas imediatas, mas a médio e longo prazo, sejam para si, familiares, pares e eventuais descendentes.

Composto por vinte capítulos e organizado em oito partes, a obra objetiva fornecer informações que podem ajudar comunidades e colaborar com intervenções em saúde mental infantojuve- 
nil durante e após grandes emergências. Nesse sentido, o conteúdo apresentado propõe-se a incentivar estudos e a fomentar políticas públicas de proteção para crianças e adolescentes.

Na primeira parte, dois capítulos apresentam um panorama sobre os desastres na população infantojuvenil; o capítulo um aborda o impacto e as repercussões pré e pós-natais do trauma, apontando bases moleculares e biológicas, com base em modelos animais e humanos. Enfatiza a gravidez como um dos períodos vitais mais vulneráveis, pela repercussão negativa dos diferentes eventos traumáticos na saúde mental na gestante, no concepto, na maternagem e na transgeracionalidade 3 . Define-se que um evento precisa ser "estressante o suficiente" para explicar os desfechos negativos e as individualidades orgânicas e subjetividades, argumentando que as variáveis "momento e cronicidade do estressor" são críticas para o seu surgimento. Ainda que seja identificado como desastre a alta prevalência das violências física e sexual em certas comunidades, critica-se aqui o pouco destaque dado no livro à magnitude das violências interpessoal e do Estado, naturalizando-se um cenário cotidiano violento e iníquo.

O capítulo dois complementa essa sessão abordando respostas em saúde pública e intervenções terapêuticas, expondo dados sobre o impacto de desastres e a incidência de transtornos mentais. Ainda que a maioria das crianças demonstre resiliência aos traumas, a magnitude dos desastres (naturais, tecnológicos e complexos) configuram-nos como um problema de saúde pública. O capítulo corrobora o que é descrito pelos relatos posteriores: desastres com lenta recuperação resultam em efeitos agudos e crônicos, alterando a trajetória desenvolvimental esperada. De forma geral, em crianças menores, prevalecem a dificuldade na aquisição de novos marcos, perdas daqueles adquiridos e reações externalizantes; em crianças maiores e adolescentes: depressão, ansiedade, estresse pós-traumático, comportamento suicida e uso abusivo de substâncias. Não é possível definir um padrão de desfecho à tipologia do desastre; porém, é essencial a compreensão de que a vulnerabilidade infantojuvenil é intensificada diante das desigualdades econômicas e de acesso à saúde, da exposição a múltiplas violências e de problemas comportamentais preexistentes.

Outros 16 capítulos descrevem experiências regionais, compondo a parte mais rica do livro. Estão organizados em seis partes, segundo temas: II - terrorismo (insurgência do Boko Haram na Nigéria; o massacre contra uma escola pública militar no Paquistão; atentado de 11 de setembro e o bombardeio na maratona de Boston, ambos nos Estados Unidos); III - terremoto e tsunamis (catástrofe de 2010, no Chile; terremoto de Wenchuan, China; terremoto de 2010, Haiti); IV - eventos nucleares (acidente de Fukushima, Japão; desastre de Chernobyl em 1986, na atual Ucrânia); V - catástrofes climáticas e geografia (furacão Katrina, Estados Unidos; uso de sistemas de informação geográfica na pesquisa sobre trauma); VI - guerra (genocídio e efeitos transgeracionais, Armênia; conflito armado, Síria; prisioneiros de guerra, Israel); VII - refugiados e direitos humanos (crianças refugiadas; crianças e conflitos armados). Apesar da diversidade de situações, não há nenhuma referência a emergências sanitárias como pandemias. Encontram-se duas breves citações sobre epidemias: a de cólera no Haiti (2010) deflagrada após as destruições por um terremoto; e a experiência japonesa com o acidente nuclear em Fukushima (2011), cujo manejo foi facilitado por uma infraestrutura criada para o enfrentamento da epidemia de SARS (2002). De modo que se observa uma lacuna na obra acerca do impacto na saúde mental infantojuvenil diante de epidemias ou pandemias, como a atual COVID-19.

A última parte do livro é dedicada a abordagens futuras e inicia com um capítulo sobre a intervenção na radicalização juvenil como estratégia de prevenção do terrorismo. Propõe-se uma correlação entre trauma, violência e radicalização juvenil, sugerindo-se ser esta última um fenômeno complexo e precursor do engajamento terrorista. Recorrendo ao modelo ecológico, adota-se a intervenção sistêmica como modelo promotor da resiliência e de prevenção da violência. Embora não descrito, destaca-se que essa radicalização se concentra no mesmo grupo etário no qual estão as maiores taxas de suicídio no mundo 4 , o que reforça a compreensão do com- 
portamento suicida como expressão de sofrimento psíquico, mas também de violência.

O livro estimula que as perspectivas, lições e críticas apresentadas sejam abstraídas e sirvam de base para a construção de modelos teóricos que capturem a essência comum dos diferentes desastres, e que comportem os vetores de prevenção e intervenção sobre a saúde mental infantojuvenil. Dois paradigmas são apresentados e apontados como promissores nesse desafio: Teoria Geral dos Sistemas e Economia Comportamental. Ainda que em bases teóricas e percursos empíricos diferentes, a sugestão é que juntos tais paradigmas poderiam colaborar para a abordagem crítica e o manejo inovador diante das grandes tragédias mundiais.

Esta resenha foi escrita durante o isolamento recomendado pelo Ministério da Saúde à população brasileira (março/2020), compreendendo a relevância de pesquisas em saúde mental infantojuvenil que abordem a temática dos desastres. Ainda que o livro não tenha contemplado realidades brasileiras, os recentes desastres de mineradoras, o genocídio da juventude negra e a atual pandemia COVID-19 são situações críticas que precisam ser analisadas para o investimento no bem-estar de crianças e adolescentes. Como sinalizado, por serem assustadores, inesperados e caóticos, a tendência pós-desastre é a geração de resposta caótica. É cedo para afirmar como e quando o Brasil e o mundo sairão desta nova pandemia, mas é certo que novos desastres virão e que a garantia da saúde mental das crianças e adolescentes é uma estratégia crítica e um trunfo à manutenção da humanidade.

Orli Carvalho da Silva Filho 1

Simone Gonçalves de Assis 2

Joviana Quintes Avanci 2

1 Instituto Nacional da Saúde da Mulher, da Criança e do Adolescente Fernandes Figueira, Fundação Oswaldo Cruz, Rio de Janeiro, Brasil.

2 Escola Nacional da Saúde Pública Sergio Arouca, Fundação Oswaldo Cruz, Rio de Janeiro, Brasil.

orli.filho@iff.fiocruz.br

\section{Colaboradores}

Todos os autores participaram da leitura do livro, elaboração e revisão da resenha.

\section{Informações adicionais}

ORCID: Orli Carvalho da Silva Filho (0000-00025268-6097); Simone Gonçalves de Assis (00000001-5460-6153); Joviana Quintes Avanci (00000001-7779-3991).

\section{Referências}

1. Lopes AMH. Múltiplos olhares sobre história única. Tempo e Argumento 2018; 25:385-409.

2. Bronfenbrenner U. Environments in developmental perspective: theoretical and operational models. In: Friedman SL, Wachs TD, editors. Measuring environment across the life span: emerging methods and concepts. Washington DC: American Psychological Association; 1999. p. 3-28.

3. Serpeloni F, Radtke KM, Hecker T, Sill J, Vukojevic V, Assis SG, et al. Does prenatal stress shape postnatal resilience? An epigenome-wide study on violence and mental. Front Genet 2019; 10:269.

4. World Health Organization. Preventing suicide: a global imperative. http://www.who.int/ mental_health/suicide-prevention/world_re port_2014/en/ (acessado em 23/Mar/2020).

Recebido em 31/Mar/2020

Aprovado em 06/Abr/2020 